\title{
A historical review of the theory of gravity-assists in the pre-spaceflight era
}

\author{
Rodolfo Batista Negri ${ }^{1}\left[\right.$. Antônio Fernando Bertachini de Almeida Prado ${ }^{1}$
}

Received: 8 October 2019 / Accepted: 29 June 2020

(c) The Brazilian Society of Mechanical Sciences and Engineering 2020

\begin{abstract}
The gravity-assist manoeuvre is a technique in which a spacecraft changes its orbital energy and angular momentum by a close-approach with a celestial body. The result is a great reduction in the use of fuel and flight time. Several interplanetary missions have applied it for this reason, like the famous Voyagers, Mariner, or Galileo. The astronomers knew the mechanics behind such concept for at least two centuries by noting the change in the orbits of the comets after passing close to Jupiter. The introduction of this phenomenon to spaceflight was a very successful story and motivated many claims that the proposal of the gravity-assist manoeuvres occurred in the early 60s. However, the idea of using such mechanism for interplanetary spaceflight can be traced back to the 20s. The dispute of being the first to have this idea contributed to throw shadow on these early pioneers. In that sense, the present paper has the goal of discussing some aspects related to the history of this manoeuvre in the pre-spaceflight era, trying to show some of the major steps made in its early history. It covers from the first studies found on this topic and goes up to the beginning of the space age, with the launching of the Sputnik satellite. This time period is chosen to bring light to these early works in which the astronomical phenomenon is introduced in the astronautics. Their importance is highlighted by putting these works under their historical context, as it shows how some of them were far ahead of their time. Among these, the work of Tsander, made in mid-20s, is outstanding.
\end{abstract}

Keywords Gravity-assist $\cdot$ Swing-by $\cdot$ Flyby $\cdot$ Astrodynamics history

\section{Introduction}

An extensive number of space missions have applied the manoeuvre known today as gravity-assist in order to accomplish their goals $[1,9,11,15,18,24-26,28,34,38,40$, $41,45,58-60,75,85,97]$. The reason is that it enables a mission to attain its objective with less expenditure of fuel and flight time. Otherwise, missions such as the ones going to the outer planets would take too long and require prohibitive amounts of fuel. The savings come from a simple close-approach with an intermediate celestial body, in certain specified conditions, harvesting an inexpressive amount of the body's momentum to change the spacecraft's orbital energy. Although this mechanism is known

Technical Editor: Jader Barbosa Jr., PhD.

Rodolfo Batista Negri

rodolfo.negri@inpe.br

1 National Institute for Space Research, São José dos Campos, Brazil by the astronomers for at least two centuries [7, 8], specially observed when a comet passes close to Jupiter, the idea of its use for space exploration purposes is not a straight line. Its importance for the space exploration has motivated many claims of "invention" or pioneering [66], which resulted in controversies, accusations and lawsuits between some great astrodynamicists [3, 16, 17, 27, 31, 78].

These controversies often overshadow the efforts of pioneering scientists who envisioned the use of celestial bodies' perturbations in the benefit of space exploration. Their achievements are often regarded as limited, because it was understood that they assumed these perturbations as undesirable, and that they should be cancelled out by brute force with fuel burning $[16,17]$. In an inattentive literature review, the narrative of a great breakthrough discovery may regard the accomplishments of these pioneers as mere unpretentious pastimes with no practical purposes, being often left aside in the technical literature. When they are cited, they are portrayed, sometimes through anachronistic lenses, as great scientists who failed to foresee the gravity-assist in its full potential. 
Fig. 1 Vector diagram to calculate patched-conics

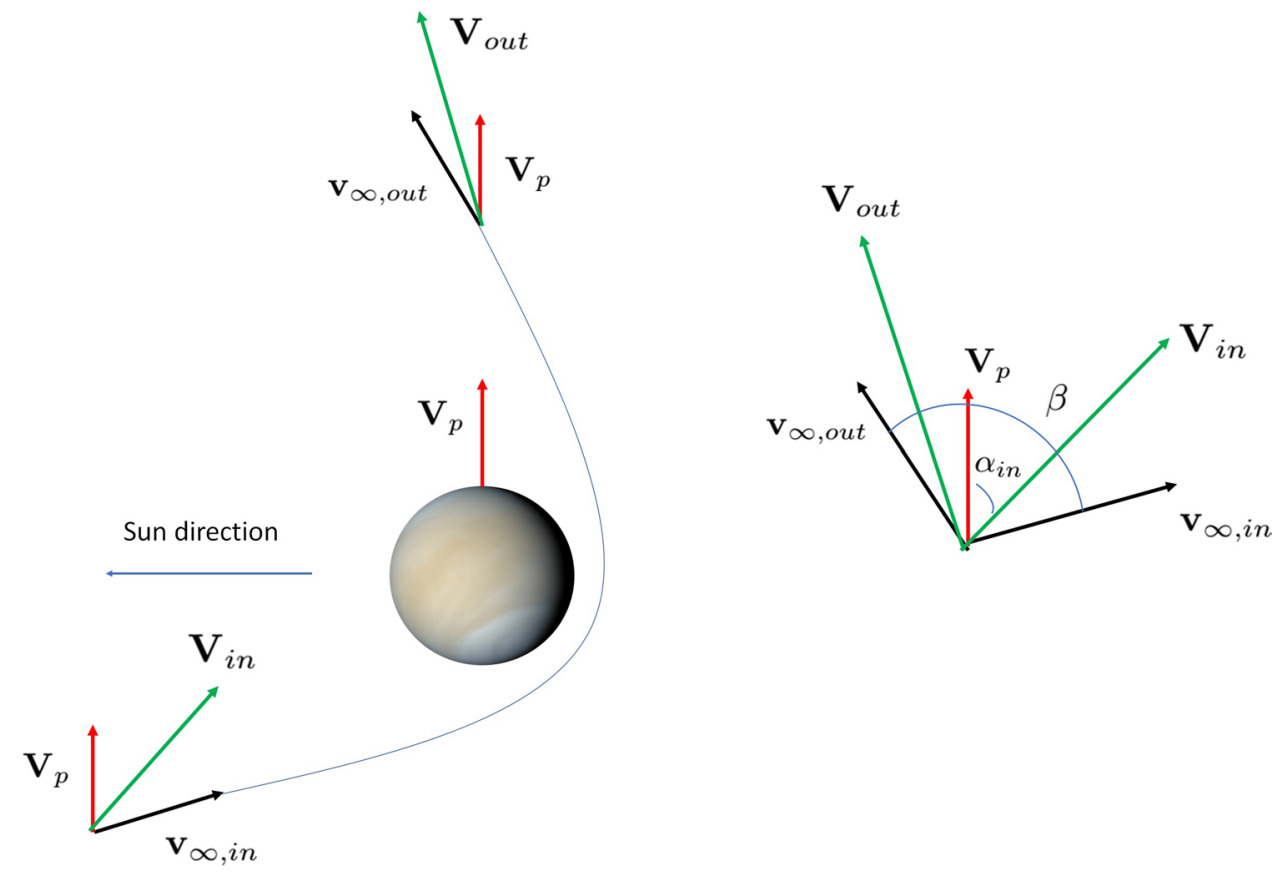

In the light of these facts, this work is a historical review of the work of these pioneers in the theory of gravity-assists. The chosen time frame is the pre-spaceflight era, up to the launch of the Sputnik 1 in 1957. The choice of this period is to concentrate and highlight the works of the scientists responsible to introduce the well-known astronomical fact in the astronautics. In the years following the Sputnik launch, the number of works considering gravity-assists and roundtrips are high $[2,4,6,13,22,23,32,35,42,43,53,63-65$, $74,80,82,89]$ and it is where lies the controversy. If they were to be considered, a very extensive and meticulous analysis would be needed. This would obscure the goal to throw light on the achievements of predecessor works. Moreover, such study would require a deeper technical understanding on sociology and history of science, which is currently beyond the scope of the present paper. ${ }^{1}$

\section{What is a gravity-assist?}

Concisely, the gravity-assist is the manoeuvre in which a spacecraft deliberately alters the geometry of its orbit through a close-approach with a moving celestial body. In practical circumstances, and following the principles of celestial mechanics, this means a three-body problem: the spacecraft, the body chosen for the gravity-assist and the celestial body orbited by the other two. The phenomenon behind the concept is already known by the astronomers at least since the observation of what is today known as Lexell's Comet. Broucke and Prado [8], and Broucke [7] showed how the concept evolved in the astronomical literature.

In the astrodynamics, a gravity-assist may be designed in two main ways. The most popular one is an approximation in which this three-body problem is split into three two-body dynamics. This is known as the patched-conics approximation. In this method, considering a gravity-assist in Venus as an example, and following Fig. 1, a heliocentric trajectory before the gravity-assist is calculated. The point where the spacecraft meets Venus is found and the spacecraft's heliocentric velocity at this point $\left(\mathbf{V}_{\text {in }}\right)$ is obtained. Using a simple vector diagram, the spacecraft's incoming velocity relative to Venus, $\mathbf{v}_{\infty, \text { in }}$, is easily calculated by knowing the Venus velocity $\mathbf{V}_{\mathrm{p}}$ and applied to find the hyperbolic trajectory relative to Venus. This, in turn, enables to obtain the spacecraft's outcome velocity, $\mathbf{v}_{\infty, \text { out }}$, and as a consequence the new heliocentric velocity $\left(\mathbf{V}_{\text {out }}\right)$ and trajectory. The approximation is good enough for most cases in the solar system. However, under some special conditions, such as large mass ratio (e.g. Earth-Moon system), a three-body problem is needed. Further considerations about the limitation of the patched-conics can be found in the literature [10, $36,67,68,76,81,90,91]$.

${ }^{1}$ It is worth to mention that such study would surely benefit from the work of Merton [62]. 


\section{In between the World Wars}

In the decade following the end of the World War I, a number of amateur rocket societies spread in different countries, such as the USA, Soviet Union, Germany and United Kingdom. The pioneers that formed these societies were much more enthusiasts rather than career scientists. The later looked to the spaceflight sceptically, and most of them were cautious to put their reputation at risk in a topic that was considered having unrealistic ideas at that time [98, p. 15]. In order to attract new members and support, these societies relied heavily on the publicity. For instance, the German Rocket Society (VfR) published, beginning in June 1927, the monthly bulletin Die Rakete (The Rocket) with many scientific articles and stories about the conquest of space [33]. In the Soviet Union, the prominent Fridrikh Arturovich Tsander was the man behind the formation of the soviet rocket societies and first publicist of the spaceflight ideas [29]. In a second-generation of Union of Soviet Socialist Republics' (USSR') publicists, the work of Nikolai Alexyevich Rynin in the nine volume encyclopaedia called Mezhplanetnyie soobshcheniya (Interplanetary Flight), published from 1928 to 1932 [98, p. 24], is outstanding. The VfR's counterpart was Willy Ley, which had knowledge of Rynin's encyclopaedia, as it can be checked in one of his papers [54].

In the volume published in 1932, Rynin introduced the reader to the mysterious Yuri Vasilievich Kondratyuk [84, p. 341]. At request of Rynin, Kondratyuk sent an autobiography piece in which he began by asserting that "the strictly personal aspects of my life are not what interest you" and that he would address only "those things which are related to my studies of the theory of interplanetary travel". The secretive approach of Kondratyuk to his life is indeed justified as today is known that his real true identity is Alexander Ignat'evich Shargei, which joined the White Army to fight the Bolsheviks in the Russian Civil War [56]. The autobiography piece sent to Rynin focused mainly in his work first published in 1929 [84, p. 341], Conquest of Interplanetary Space [46]. This work is an extension of a collection of manuscripts called "To Those Who will Read in Order to Build", dated back to 1918-1919 and modified throughout his life [61, p. 49].

One of the first records of a proposal of a gravity-assist is in this manuscript, which received an English translation in 1965 [47]. Kondratyuk laid in two paragraphs a vague concept of gravity-assist [47, p. 45]. In the first paragraph, he suggested that a close approach between the spacecraft and the satellite of a planet may be used to "gather velocity" for a solar system journey and to "absorb velocity" when it is returning. In the second paragraph, a figure similar to Fig. 2 was used to explain that two approaching

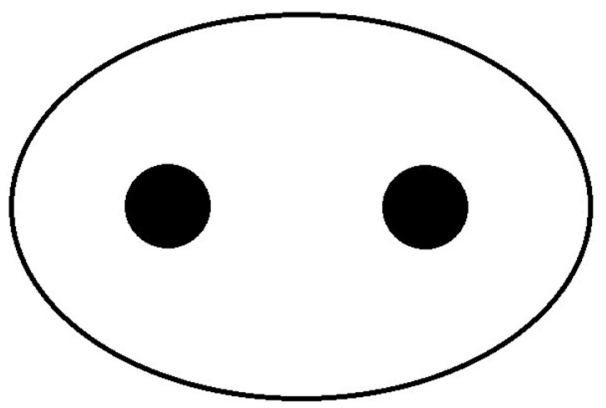

Fig. 2 Figure similar to the one found in Ref. [47]

bodies may be used to continuously increase the velocity of a vehicle describing a trajectory around them. $\mathrm{He}$ correctly remembered that the vehicle will lose velocity if the bodies are moving apart. Sadly, this piece of work about gravity-assists received no later development and it was not even published in the Conquest of Interplanetary Space [46].

Broucke and Prado [8] and Flandro [27] argued that the Austrian mechanical engineer, Guido von Pirquet, was also one of the first to develop the concept of gravity-assist. Von Pirquet was the Secretary of the Society of High-Altitude Exploration, what may be referred as Austrian Rocket Society [98, p. 31]. In the period 1928-1929, he published in the Die Rakete a series of articles about interplanetary travel, which included travels to Mars, Venus and Jupiter. His supposed developments on gravity-assists are among these articles under a section entitled Die Jupiterreise (Jupiter's Journey), published in 1928-1929, in two different volumes of the Die Rakete [94, 95].

In the first part of the article [94], von Pirquet gave a brief discussion in choosing one transfer orbit to Jupiter. He then introduced the velocity vector diagrams also presented in Broucke and Prado [8], which is equivalent to the one presented in Fig. 1. These vector diagrams are very similar to the method used in the patched-conics approach. Von Pirquet applied them to discuss how the spacecraft approaching Jupiter could correct its trajectory and the processes and $\Delta V$ s necessary to insert the spacecraft into a Jovian orbit. The supposed gravity-assist on Jupiter is discussed in the second part of the article [95], in which von Pirquet applied the vector diagrams to calculate the hyperbola relative to Jupiter. Although he was able to calculate that the velocity after the passage has changed, he did not explicitly state that the spacecraft acquired a $\Delta V$. He concentrated on obtaining an outgoing heliocentric velocity after the flyby of the same magnitude, in the opposite direction and symmetric to the incoming velocity. To accomplish this task, it was introduced what he called a manoeuvre velocity $v_{\mathrm{m}}$, in order to counteract the implicit $\Delta V$ and direction change. Von Pirquet noted that, if the perijove of the flyby hyperbole is parallel 
to the direction of the Sun, no manoeuvre velocity $v_{\mathrm{m}}$ is needed.

The lack of comments on the velocity gained by the spacecraft is an indicative that von Pirquet gave it no practical importance. Less likely, considering his high skills, he even did not notice that this fact happened in the passage, believing that it was only a matter of changing the velocity direction. In either case, von Pirquet did not use deliberately the approximation to Jupiter in the benefit of the trip (saving fuel or time, for instance). Therefore, he did not propose a gravity-assist. Nevertheless, this is not a detraction to his great work, since he was able to use the velocity vector diagrams to predict the hyperbolic Jovian trajectory and the outgoing heliocentric velocity in order to complete his visionary Jupiter's journey. These are among many other important contributions he made, such as the proposal of space stations [5, 39, 57].

In between the works of Kondratyuk and von Pirquet, the soviet engineer Friedrich A. Tsander wrote in 1924-1925 the article "Flights to Other Planets-The Theory of Interplanetary Travel" [93]. Tsander was a key figure in the USSR' space exploration movement. He was an enthusiastic with a high level of technical and scientific skills. He gave many talks and was behind the creation of the Society for the Study of Interplanetary Travel in 1924 [29] and the Group for the Study of Reactive Motion (GIRD) by the 30s [88, p. 114]. The "Flights to Other Planets-The Theory of Interplanetary Travel" [93] would be published only in 1932, in the book Problems of Flight by Jet Propulsion [87, p. 3]. Tsander made an analysis of gravity-assists from section 5 to 7, which were, respectively, named: "Modification of Flight Trajectory Around the Sun by Planet's Gravitational Fields", "Kinect Energy Increment of Spaceship Flying Around Planet" and "Flight Around Planet's Satellite for Accelerating or Decelerating Spaceship".

In the first of these sections, Tsander began by assuming that the sphere of influence of the planet is so small that the trajectory modification can be approximated to take place at one point [93, p. 278]. He then proceeded to obtain relations between the velocities and angles involved in the dynamics. In the next section, Tsander effectively derived and calculated the gravity-assist. In the first lines [93, p. 280], he presented the following equation for the variation of energy in a planar gravity-assist, very similar to the one taught in undergraduate orbital mechanics classes today:

$\Delta E= \pm 2 v_{\infty} V_{\mathrm{p}} \sin \left(\alpha_{\text {in }} \pm \frac{\beta}{2}\right) \sin \left(\frac{\beta}{2}\right)$,

where as shown in Fig. $1, v_{\infty}$ is the planetocentric velocity at infinity, $V_{\mathrm{p}}$ is the heliocentric velocity of the planet, $\alpha_{\text {in }}$ is the angle between the incoming heliocentric velocity of the spacecraft and $\mathbf{V}_{\mathrm{p}}$, and $\beta$ is the turning angle. Although
Eq. (1) is not a novelty in the literature (it can be found as early as 1878 [73, p. 175] in the astronomy), this is the first time such equation is found in the astronautics literature, with variables of interest under a mission perspective. The conditions for a maximum variation of energy is then calculated and the values corresponding to each planet of the solar system is displayed in a table [93, p. 284] (these values, as calculated by Tsander, are, from Mercury to Neptune in $\mathrm{km}^{2} / \mathrm{s}^{2}: 193.2,315,283,109.1,661,278,117.7$ and 114.4). He noted that the energy increase per unit mass is larger for Jupiter $\left(661 \mathrm{~km}^{2} / \mathrm{s}^{2}\right)$, followed by Venus $\left(315 \mathrm{~km}^{2} / \mathrm{s}^{2}\right)$ and the Earth $\left(283 \mathrm{~km}^{2} / \mathrm{s}^{2}\right)$ [93, p. 283]. The section ended with Tsander presenting the following equation for the $\Delta V$ obtained from a gravity-assist:

$\Delta V=2 v_{\infty} \sin \left(\frac{\beta}{2}\right)$,

with an extensive derivation of the conditions for a maximum value. He also obtains a planar non-vectorial form of the equation marked as 8 in Ref. [66] by Minovitch, who claimed to have discovered it. The last section was basically an application of the concepts derived in his work to find the conditions that could produce the maximum $\Delta V$ for a spacecraft departing from a planet. In order to do so, Tsander applied his formulation on gravity-assists and proposed to make the manoeuvre around the planet's moon.

Although the work of Tsander on gravity-assists is only one among his other prolific works (e.g. his obsessive idea on a winged rocket that used its fuselage as propellant [71]), this should be understood under the historical circumstances of that time, in which they still had to overcome the Earth's gravity field. Tsander showed to understand the advantages of gravity-assists when, in the work outlined above, he obtained the maximum energy variation for each planet and proposed lunar gravity-assists. This is also evidenced in a book proposal dated back to October 17, 1926. He proposed, under a chapter V called "The Theory of Interplanetary Flight", two sections related to gravity-assists named [93, p. 384]:

- Change of flight trajectory about the Sun under the influence of the planets. The advantage of increasing or decreasing the flight velocity;

- Orbiting the Moon with the purpose of accelerating or decelerating the spaceship. Maximum change in velocity.

Dowling et al. [17, p. 368] stated that Tsander viewed planetary perturbations as "annoying (and dangerous) that should be avoided". This appears to contradict the Tsander quotes mentioned in the paragraphs above. Their conclusion came from an excerpt [93, p. 240] in which Tsander commented on an "inaccurate injection of a spaceship into orbit". Although 
the translation is a little confusing, it appears Tsander was worried that any error in correctly meeting the planet may transform what should be an orbit injection into a passage that could send the spacecraft towards the Sun or outside the solar system. Therefore, he was not making a point against gravity-assists. He was rather utilizing his knowledge in the mechanism of gravity-assists to alert to the disastrous outcome that an orbital injection error could cause. Dowling et al. [17, p. 368] proceeded arguing that, as Tsander recognized the Hohmann transfer as the minimum energy transfer, he was "very far from anticipating the innovation" of interplanetary multiple gravity-assists. Some excerpts from Tsander give indications in the opposite direction.

In an autobiography dated to March 1927, Tsander wrote a list of his contributions to the astronautics [93, p. 15]. This text was sent to Rynin and published in 1929 [83, p. 185]. In his list of great contributions, the 8 th item is:

A proposal for flight around planets, in their atmospheres, or out of them, in order to increase the speed of flight (thus gaining energy during interplanetary flights).

In the article "Problems of Super-Aviation and Immediate Objectives of Space Research", he enumerated useful methods for interplanetary journeys, and among them [93, p. 374]:

The flight trajectories may sometimes be chosen so that the vehicle travels round planets or outside their atmosphere. In this case the flight velocity can be increased. Revolution about the Moon may raise the flight velocity by about $2 \mathrm{~km} / \mathrm{sec}$. A ship travelling around the Earth outside the atmosphere will gain about $10 \mathrm{~km} / \mathrm{sec}$, and inside the atmosphere, 50-55 $\mathrm{km} / \mathrm{sec}$. A ship travelling round Jupiter outside its atmosphere may increase its flight velocity by $24 \mathrm{~km} /$ sec. [sic]

In the face of all this, Tsander had not only a high understanding of gravity-assists, but he also could foresee the great advantage it would play in interplanetary travel. In a historical context in which these pioneers were seem as "crackpots" [98, p. 15], when almost every single piece of a space exploration travel should be developed and with no aid of computers, which played a central role in the later space programs, the work of Tsander is an incredible masterpiece. This is even more exceptional when considering other brilliant pioneers, such as Oberth, von Pirquet, Hohmann, Tsiolkovskii that never considered gravity-assists as a mean for interplanetary travel. Moreover, it is hard to believe that Tsander's ideas on gravity-assists had no impact on later soviet astrodynamicists. Tsander gave many talks in the 1920s, was one of the founders of the GIRD, and considered by one of the men behind the first steps of the USSR in the space race, Sergei Korolev, as a mentor [88, p. 141].

Sadly, Tsander died 1 year after the publication of the Problems of Flight by Jet Propulsion, in 1933. Suffering from exhaustion due to overwork, Tsander contracted typhus in a travel to a health spa, dying on March 28 [87, p. 6]. The fortune of his GIRD's fellows was not much better. The Stalin's rule resulted in the Great Purge. Some of the former GIRD members were arrested by the NKVD (People's Commissariat for Internal Affairs) and sent to Gulags [87, p. 10]. This included Sergei Korolev, that was sent to one of the most brutal of them, Kolyma, under false accusations of being a member of an anti-Soviet organization [87, p. 12]. Kondratyuk did not have a good fortune either. He died on February 23, 1942, after being recruited to defend Moscow against the Nazis [56]. In this same year, the famous soviet publicist, Rynin, died in the Nazi siege to Leningrad. Regarding von Pirquet, he published in astronautical journals until his death in the 60s $[92,96]$. However, the Austrian rocket societies ended their operations in 1938, with the Anschluss [98, p. 33]. The magazine Die Rakete stopped its activities in 1929 because of many members failing to pay their dues, and the decision of the VfR to concentrate resources in experiments [69]. Willy Ley immigrated to the USA in 1935 to escape the Nazis [71], establishing himself as an authority on rockets and space travel [33]. Much of the other members of the VfR would be part of the Peenemünde group working on the V-2 missiles during the World War II [70].

\section{In the trail to conquest the space}

The World War II was a break in the international space research of the 20-30s. With the end of the war, there was a revival in this movement, culminating with the formation of the International Astronautical Federation (IAF) in 1951 [33]. The USA got most of the engineers of the Peenemünde with the Project Paperclip [14], including the famous Wernher von Braun and a young engineer, which would play a role in gravity-assist theory, known as Krafft Arnold Ehricke. Tsander's former GIRD fellow, Korolev, was released in August 1944 and was part of the Soviet inspection team of the Nazi's V-2 sites [72, p. 21]. The former VfR's publicist, Willy Ley, was active in the period, the first important work at that time was his paper "Rockets: The future of travel beyond the stratosphere" [55], published in 1944 [33]. In the post-war period, the British Interplanetary Society (BIS), founded in 1933, would become one of the largest spaceflight societies [33]. Its Journal of the British Interplanetary Society (JBIS) would be the journal in which many important astrodynamicists would publish in the years 
to come, which included the first work on gravity-assists after Tsander.

This first work is of the British mathematician Derek Frank Lawden, published in 1954 and entitled "Perturbation Manoeuvrés" [51] (how he called the gravity-assist). Lawden applied the velocity vector diagrams to calculate the hyperbolic flyby trajectory and noted that the approach before the manoeuvre can be corrected with small thrusts, as already noted by von Pirquet [94]. He exemplified the manoeuvre by calculating it for the Moon and Mars. The first was aimed to escape the Earth for an interplanetary journey, as already proposed by Kondratyuk [47] and Tsander [93]. In his conclusions, Lawden pointed out that a considerable saving in fuel can be obtained by making such manoeuvre in asteroids for a journey between two planets. He probably did not make such estimative. A detailed calculation would indicate that the bending angle for an asteroid would be very small, because of its small mass, in a practical range of incoming heliocentric velocities. Therefore, a very small energy variation would be given to the spacecraft. In a later work [52], Lawden stated that "the best way of utilising such perturbation effects is not known", which indicates that much still to be done at the time, at least in the western world.

An interesting fact in the paper of Lawden must be commented. In the first line of the introduction section, he readily noted that "a number of writers have suggested" the manoeuvre, but it "does not appear to be widely known". He did not cite the writers he refer to, so it remains the question on if he had read their works or if he had heard about these ideas. The small thrusts to correct the trajectory of approach to the planet could be the case of a simple natural concern in advocating that such close approach to a planet can be, precisely and safely, made at low fuel expenditures. However, it should not be discarded the possibility that Lawden was somehow inspired by von Pirquet [94]. There were some references to works of von Pirquet in the 50s [20,49], and a work of von Piquet himself in the JBIS [96]. Moreover, von Pirquet was awarded as honorary fellowship of the BIS in 1949.

Certainly, Lawden did not have access to the work of Kondratyuk [47], because the manuscript referring to gravity-assists was only published in 1964 [56]. He also probably did not have access to the work of Tsander [93], because Eq. (1) and the maximum energy variation calculated by Tsander for each planet would easily show him that asteroids are not good sources of free energy in a journey between two planets. With the death of Stalin in 1953, the soviet scientists could re-establish their cultural exchange with their western counterparts that was suspended since the mid-30s [79, p. 67]. It could be the case Lawden had heard about the proposals of Kondratyuk and Tsander in cultural exchanges with soviet scientists, specially the ones of Tsander, because of his influence in the rocket community of the Soviet Union $[29,88]$. However, this cultural exchange is much less likely to have occurred. For instance, only two observers of the USSR were sent to the 6th International Astronautical Congress (IAC) of the IAF held in 1955, in Copenhagen [86].

Another hypothesis is that because of the contact between Ley and Rynin, the idea of gravity-assist originated with Tsander was somehow amorphously wandering around in the West. In his 1944's book [55], Ley cited Rynin and his encyclopaedia a few times in the text. The works of Kondratyuk [46] and Tsander [93] are listed in Cyrillic in the bibliography, albeit no reference to these works (neither to gravity-assists) are made in the text. Nevertheless, one fact is certain, the proposal of using the momentum of a celestial body to gain energy for a spacecraft's journey was already known at that time. Although not "widely known", the imprecise statement "a number of writers" is an indicative that the gravity-assist proposal by pioneers was in the social imaginary of some astrodynamicists.

In the year of 1956, a great advancement on the theory of gravity-assists is registered in the literature. This is the work of Gaetano A. Crocco, founder of the Italian Rocket Association (AIR) [37], and presented in the 7th IAC, Rome, hosted by AIR. In the paper "One-year Exploration-trip Earth-Mars-Venus-Earth" [12], Crocco elaborated for the first time what could be considered as the first work of freefall multiple gravity-assists. In this concept, the spacecraft makes all the manoeuvres needed to change its trajectory by means of multiple gravity-assists with one or more celestial bodies. The objective of Crocco was to find a trajectory in which a manned mission with reconnaissance purposes could visit Mars and Venus, returning back to Earth, with a lower expenditure of fuel and time than other works found in the literature at that time [12, pp. 227-228]. In order to do so, he divided the work in two parts.

In the first part, he considered his round-trip without the perturbations of Mars and Venus, in a constant elliptical trajectory launched from the Earth, which is nowadays known as Crocco's Grand Tour. He concluded his task remarking the advantage of this trajectory to previous ones, both in terms of fuel and flight time [12, p. 235]. Among other final considerations, Crocco noted that these calculations could only be true if the spacecraft passed very far from Mars and Venus, due their perturbations. However, avoiding such close-approaches would be detrimental to the "exploration scope" of the trip [12, p. 239]. Crocco pondered that the perturbations are rather a chance for "free maneuvers", the paper of Lawden [51] was cited at this point [12, p. 239], and thus the scientific purpose of the travel could be kept.

The perturbations were considered in the second part. After presenting the velocity vector diagrams and the equations he would later apply, very similar to the ones found in Lawden [51], Crocco made some considerations 
about choosing in which point of the orbit to intersect Mars and Venus. He then calculated the gravity-assist in Mars, neglecting the Venus' perturbations and showed how the spacecraft would delay to encounter the Earth for different cases of Martian periapsis [12, p. 248]. He finally added the Venus' perturbations [12, p. 249] and, by adjusting the turning angle of the Venusian gravity-assist, he found the trajectory in which the spacecraft would meet the Earth. This was made for two different conditions, represented in two different figures, considering a Martian gravity-assist with a periapsis value equals to the Mars' radius and to zero.

Dowling et al. [16, p. 86] stated that Crocco "viewed planetary perturbations as annoying disturbances" and that his trajectory cannot be considered a "gravity-propelled multi-planet trajectory" (i.e. free-fall multiple gravity-assists for interplanetary travel) because they were used to "preserve [...] an eccentric constant elliptical path" [16, p. 89]. The first claim is contradicted by Crocco's own words [12, p. 239]: “... perturbations can constitute for the pilot exceptional chances of free manoeuvres, that is without the consumption of propellent". Regarding the second affirmative, Crocco was not concentrated in preserving the "constant elliptical path". In fact, a simple check in the last two figures of Crocco's paper, which show his different tries to make the spacecraft meets the Earth, shows the opposite. Crocco was beneficially and deliberately trying to use the gravity-assist in both planets to obtain a trajectory as advantageous as the Crocco's Grand Tour (in terms of flight time and launch velocity) that could make a close-approach to both planets without any additional fuel expenditure.

Dowling et al. [16, p. 89] also argued that it cannot be considered a "gravity-propelled multi-planet trajectory" because it did not reduce the launch hyperbolic velocity, which could be done by reversing the order of the gravityassists (i.e. encountering Venus first). However, Dowling et al. did not mention that Crocco already reduced the total amount of fuel expenditure when he noted that the perturbations are a source of "free maneuvers" that enable the spacecraft to have close-approaches with the perturbing bodies without expending any additional fuel [12, p. 239]. If Crocco did not recognize the "gravity-propelled" nature of the manoeuvre, he would add a corrective $\Delta V$ similar to the one introduced by von Pirquet [95].

Additionally, the fact that Crocco did not recognized a first gravity-assist in Venus as more advantageous is not an argument against its pioneering in multiple gravity-assists. This is a consequence of the incremental steps of the historical development of the theory of gravity-assists. As noted before, Lawden is one of the references for Crocco. If any of them had integral access to the work of Tsander [93], they would possibly recognize the great advantage of making the first gravity-assist in Venus.
In 1955, about 1 year before Crocco's paper, the White House announced a satellite project for the International Geophysical Year (IGY). The IGY took place in 1957-1958, engaging sixty-seven countries in an effort to study the Earth, including its atmosphere and oceans [48]. A couple of weeks after the White House announcement, during the 6th IAC in Copenhagen, a Soviet representative announced that the USSR would launch a satellite too [72]. Neufeld [72, p. 41] argued that this statement might lacked top-level political backing, and Korolev was one of the men behind it. In the USA, Korolev's rival, Wernher von Braun, had its rocket proposal rejected in favour of the Vanguard rocket. The spaceflight was on the horizon.

\section{In the dawn of the interplanetary travel}

On 4 October 1957, the Sputnik 1 was launched and the Earth's gravity was finally proved to be overtaken. This resulted in a series of measures taken by the US government, as the creation of the NASA (National Aeronautics and Space Administration), and the mark for the beginning of the "space race" [50, 87]. In the following years, a higher and more sophisticated number of proposals for interplanetary missions would appear. As one could expect, the gravity-assists would become more important in the years to come. In the same October of 1957, two papers related to gravity-assists mark this trend. They were presented in the 8th IAC, in Barcelona. The paper of Krafft A. Ehricke entitled "Instrumented Comets-Astronautics of Solar and Planetary Probes" [21] and the "Some Problems Relating to the Dynamics of the Flight to the Moon" [99] by Vsevolod A. (Y)Egorov.

The first spacecraft considered to make a gravity-assist is Luna 3, in 1959, changing its inclination in order to reapproach the Earth by the northern hemisphere. One of the studies behind the trajectory design of this mission [77, p. 146] was a work of Egorov published in 1957 that was translated to English in 1958 [19]. Egorov was one the Keldysh's Boys [87, p. 103], a group of young scientists that was behind much of the work done by the Soviets in the space race. The paper presented in the 8th IAC appears to be a summary of the previous work of 1957 [99]. In both works, some papers of Lawden were cited and in the IAC's paper he even referred to the gravity-assist as "perturbation maneuvers". In the section 11 [19], Egorov considered gravity-assists in the Moon for a interplanetary space travel. This is the same idea of Kondratyuk and Tsander, albeit there is no reference for them. The importance of Egorov's work is that, for the first time, a gravity-assist was considered using a three-body problem as the mathematical model.

The other work is of Krafft Ehricke, one of the former members of the group working on the V-2 missile and 
recruited by the US military at the end of the WWII [30, 44]. The work presented in Barcelona [21] can be considered as a general study in advocating for unmanned interplanetary exploration with probes ("instrumented comets"). He considered many different types of space probes (balloons, solar radiation pressure propelled, thermonuclear, etc), different scientific goals (e.g. measurement of interplanetary matter), etc. Even social, political and cultural perspectives were discussed. Trajectories to the Moon, Venus, Mars and Jupiter were considered in details. In the case of the Moon, a three-body problem was applied and compared to a four-body problem in order to highlight the importance of the Sun after a Moon closeapproach. All astrodynamicists should revisit this incredible piece of work.

Regarding the gravity-assist, Ehricke [21] expanded the analytical formulation of Lawden [51]. He was aware that the astronomers knew for a long time that perturbations can increase or decrease the energy of a small body and argued that this could be exploited by "instrumented comets" in different planets than Jupiter [21, p. 6]. The missing piece in the works of Lawden and Crocco, the equation for the energy variation, is derived by Ehricke in a differential version of Eq. (1). He showed a deep understanding of all the physics behind the gravity-assist. Although this enabled him to note that the manoeuvre is also dependent on the mass [21, p. 83], he only advocated to use the gravity-assist in Venus for travels to Mercury, while for travels beyond the asteroid belt a gravity-assist in Mars was recommended [21, p. 124]. It might be the case he simply did not envisioned that planets interior to the orbit of the Earth could be used to travel to planets exterior to the Earth's orbit. Other possible reason is that Ehricke was highly worried with technical practical issues of applying such manoeuvres, specially regarding guidance, navigation and control: "The principal difficulty in using gravitational navigation [how he refers to gravity-assist] lies in the fact that this method is very sensitive. The approach to the perturbing body must be quite accurate. Small errors at the entrance into the perturbative field result in much greater errors at the exit" [21, p. 82]. These considerations are very similar to those of Tsander about the "inaccurate injection of a spaceship into orbit".

According to Flandro [27], Ehricke made presentations in the Space Technology course at UCLA, showing in full detail his ideas on gravity-assists. He also mentioned that Ehricke's works were the first seeds for his later work that led to the Voyager missions [26]. With the work of Ehricke in 1957 [21], the theory needed to the design of gravity-assists was available in the astrodynamics literature. However, the best way to utilize them in practice was not completely covered. This was the work of the next years.

\section{Conclusion}

A review of the works on gravity-assists in the pre-spaceflight era was made. The objective was to bring light to these works and their authors, in order that the community can evaluate their real achievements, contributions and give them their proper deserved credits. The advancements and authors were put under their historical context. This is important to understand how their achievements were surprisingly advanced when developed, and how they are possible related. Among all of these, the work of Tsander in the 1920s is outstanding. He not only had a full understanding of the dynamics behind gravity-assists, but also could foresee the great advantage of using it for interplanetary travel.

The objective of bringing light to the work of these pioneers would not be possible if this historical review was extend to post-Sputnik years. The number of works are tremendous and the controversies would demand an extensive and meticulous analysis and discussion. Nevertheless, a proper review on these works of the early-days postSputnik is highly important. As showed, albeit Ehricke had a full understanding of gravity-assists, he did not envision the application of gravity-assists in its full potential. Therefore, such review would be focused on works that understood all the possibilities enabled by gravity-assists, which are well known today.

Additionally, we hope that this work may serve as a motivation for historians of science to complement it. A research on the Soviet journals about the influences of Tsander's gravity-assists would be a great advancement. Considering that Willy Ley might be the link between the works of Tsander and Lawden, a meticulous and extensive research on Willy Ley's publications and archives for any mention on gravity-assists or Tsander should clarify this hypothesis.

Acknowledgements The authors wish to express their appreciation for the support provided by Grants \# 406841/2016-0 and 301338/2016-7 from the National Council for Scientific and Technological Development (CNPq); Grants \# 2017/20794-2, 2015/19880-6 and 2016/24561-0 from São Paulo Research Foundation (FAPESP) and the financial support from the Coordination for the Improvement of Higher Education Personnel (CAPES). The authors also wish to express the appreciation for the copies of Guidon von Pirquet works provided by Linda Hall Library through Dr. Benjamin Gross. The contact came to be after reading the article about von Pirquet by Dr. William B. Ashworth, Jr. in the library's website. We also thank the personnel working at the INPE's (National Institute for Space Research) library for finding several papers used in this research.

\section{References}

1. Anselmi A, Scoon GE (2001) Bepicolombo, ESA's mercury cornerstone mission. Planet Space Sci 49(14-15):1409-1420 
2. Battin RH (1959) The determination of round-trip planetary reconnaissance trajectories. J Aerosp Sci 26(9):545-567

3. Battin RH (1996) On algebraic compilers and planetary fly-by orbits. Acta Astronaut 38(12):895-902

4. Battin RH, Laning JH Jr (1961) A navigation theory for roundtrip reconnaissance missions to venus and mars. Planet Space Sci $7: 40-56$

5. Besser B (2001) Contributions of Austrian pioneers to early European rocketry. In: 39th Aerospace sciences meeting and exhibit, $p$ 174

6. Breakwell JV (1961) Researches in interplanetary transfer. ARS J 31(2):201-208

7. Broucke RA (2002) On the history of the slingshot effect and cometary orbits. Adv Astronaut Sci 109:1927-1939

8. Broucke RA, Prado A (1993) Jupiter swing-by trajectories passing near the earth. Adv Astronaut Sci 82(2):1159-1176

9. Campagnola S, Jehn R, Corral C (2004) Design of lunar gravity assist for the BepiColombo mission to mercury. In: Paper AAS, pp 4-130

10. Campagnola S, Russell RP (2010) Endgame problem part 2: multibody technique and the tisserand-poincare graph. J Guid Control Dyn 33(2):476-486

11. Carlson R, Judge D (1974) Pioneer 10 ultraviolet photometer observations at jupiter encounter. J Geophys Res 79(25):3623-3633

12. Crocco GA (1956) One-year exploration-trip earth-mars-venusearth. In: Proceedings of the VIIth international astronautical Congress, Rome, pp 227-252

13. Cutting E (1965) Trajectory analysis of a 1970 mission to mercury via a close encounter with venus. In: 2 nd Aerospace sciences meeting, $\mathrm{p} 90$

14. DeVorkin D (1987) Organizing for space research: the V-2 rocket panel. Hist Stud Phys Biol Sci 18(1):1-24

15. Diehl R, Nock K (1979) Galileo jupiter encounter and satellite tour trajectory design. In: American Institute of Aeronautics and Astronautics conference

16. Dowling RL, Kosmann WJ, Minovitch MA, Ridenoure RW (1990) The origin of gravity-propelled interplanetary space travel. In: Proceedings of the 41st international astronautical federation

17. Dowling RL, Kosmann WJ, Minovitch MA, Ridenoure RW (1999) The effect of gravity-propelled interplanetary space travel on the exploration of the solar system-historical survey, 1961-2000. In: IAF, International Astronautical Congress, 50th, Amsterdam

18. Dunne JA, Burgess E (1978) The voyage of Mariner 10. National Aeronautics and Space Administration SP 424

19. Egorov VA (1958) Certain problems of moon flight dynamics. The Russian Literature of Satellites 107-174 (English translation of $\mathrm{O}$ nekotorykh zadachakh dinamiki poleta $\mathrm{k}$ Lune)

20. Ehricke KA (1954) A new supply system for satellite orbits-part 1. J Jet Propuls 24(5):302-309

21. Ehricke KA (1957) Instrumented comets-astronautics of solar and planetary probes. In: Proceedings of the 8th International Astronautical Congress, Barcelona, vol 493-57. American Rocket Society, pp 74-126

22. Ehricke KA (1963) Orbital operations. In: Advances in space science and technology, vol 5. Academic Press Inc, Cambridge, pp 231-325. https://doi.org/10.1016/B978-1-4831-9963-4.50012-9

23. Ehricke KA, Merrill G, Street R (1960) Space flight. Phys Today 13:62

24. Fimmel RO (1977) Pioneer odyssey. NASA STI/Recon Technical Report N 77

25. Fimmel RO, Van Allen J, Burgess E (1980) Pioneer: first to jupiter, saturn, and beyond. NASA Special Publication 446

26. Flandro G (1966) Fast reconnaissance missions to the outer solar system utilizing energy derived from the gravitational field of jupiter. Earth 108:6-1
27. Flandro G (2001) From instrumented comets to grand tours-on the history of gravity assist. In: 39th Aerospace sciences meeting and exhibit, p 176

28. Fox N, Velli M, Bale S, Decker R, Driesman A, Howard R, Kasper JC, Kinnison J, Kusterer M, Lario D et al (2016) The solar probe plus mission: humanity's first visit to our star. Space Sci Rev 204(1-4):7-48

29. Freeman M (2003) The contributions of Fridrikh Tsander: a memoir. Acta Astronaut 52(8):591-599

30. Freeman M, Ehricke K, Schmitt H (2009) Krafft Ehricke's Extraterrestrial imperative. Apogee Books, Burlington

31. Gallentine J (2009) Ambassadors from earth: pioneering explorations with unmanned spacecraft. University of Nebraska Press, Lincoln

32. Gedeon G (1962) Round-trip trajectories to mars and venus. AAS Prepresent 62:30

33. Geppert AC (2008) Space personae: cosmopolitan networks of peripheral knowledge, 1927-1957. J Mod Eur Hist 6(2):262-286

34. Glassmeier KH, Boehnhardt H, Koschny D, Kührt E, Richter I (2007) The Rosetta mission: flying towards the origin of the solar system. Space Sci Rev 128(1-4):1-21

35. Gobetz FW (1963) Optimum transfers between hyperbolic asymptotes. AIAA J 1(9):2034-2041

36. Greenberg R, Carusi A, Valsecchi G (1988) Outcomes of planetary close encounters: a systematic comparison of methodologies. Icarus $75(1): 1-29$

37. Guardabassi GO (2007) The dawn of control science in italy from intuitive engineering to modern control theory and automation technology. Eur J Control 13(1):36-48

38. Guo Y, Farquhar RW (2008) New horizons mission design. Space Sci Rev 140(1-4):49-74

39. Hacker BC (1974) The idea of rendezvous: from space station to orbital operations in space-travel thought, 1895-1951. Technol Cult 15(3):373-388

40. Hansen CJ, Bolton SJ, Matson DL, Spilker LJ, Lebreton JP (2004) The Cassini-Huygens flyby of jupiter. Icarus 172(1):1-8

41. Hechler M (1997) Rosetta mission design. Adv Space Res 19(1):127-136

42. Hollister W, Prussing J (1965) Optimum transfer to mars via venus. In: Thermophysics specialist conference, $\mathrm{p} 700$

43. Hunter M II, London H (1965) Propulsion for unmanned exploration of the solar system. Unmanned Spacecr Meet 1965:1408

44. James GS (2015) A background of memories of working with Dr. Wernher von Braun, Krafft Ehricke and members of the Peenemunde Group. Acta Astronaut 113:212-220

45. Kohlhase C, Penzo P (1977) Voyager mission description. Space Sci Rev 21(2):77-101

46. Kondratyuk YV (1965) Pioneers of rocket technology. In: Conquest of interplanetary space. National Aeronautics and Space Administration. English translation of Pionery raketnoy tekhniki-Kibal'chich, Tsiolkovskiy, Tsander, Kondratyuk-Izbrannyye trudy

47. Kondratyuk YV (1965) Pioneers of rocket technology. In: To whomsoever will read in order to build. National Aeronautics and Space Administration. English translation of Pionery raketnoy tekhniki-Kibal'chich, Tsiolkovskiy, Tsander, KondratyukIzbrannyye trudy

48. Korsmo FL (2004) Shaping up planet earth: the international geophysical year (1957-1958) and communicating science through print and film media. Sci Commun 26(2):162-187

49. Krull AR (1956) A history of the artificial satellite. J Jet Propuls 26(5):369-383

50. Launius RD (2010) An unintended consequence of the IGY: Eisenhower, Sputnik, the founding of NASA. Acta Astronaut 67(1-2):254-263 
51. Lawden D (1954) Perturbation maneuvers. J Br Interplanet Soc 13(5):329-334

52. Lawden DF (1955) Dynamic problems of interplanetary flight. Aeronaut Q 6(3):165-180

53. Lawden DF (1963) Optimal trajectories for space navigation, vol 3. Butterworths, London

54. Ley W (1935) Rocket propulsion: a résumé of theory with an account of the practical experiments made to date. Aircr Eng Aerosp Technol 7(9):227-231

55. Ley W (1944) Rockets: the future of travel beyond the stratosphere. Viking Press, New York

56. Maksimov A (2007) FA Zander and Yu. V. Kondratyuk, pioneers of rocket engineering. Thermophys Aeromech 14(4):469-492

57. Mark H (1987) The space station: a personal journey. Duke University Press, Durham

58. Matousek S (2007) The Juno new frontiers mission. Acta Astronaut 61(10):932-939

59. McNutt RL Jr, Solomon SC, Gold RE, Leary JC, Team M et al (2006) The messenger mission to mercury: development history and early mission status. Adv Space Res 38(4):564-571

60. McNutt RL Jr, Solomon SC, Grard R, Novara M, Mukai T (2004) An international program for mercury exploration: synergy of messenger and bepicolombo. Adv Space Res 33(12):2126-2132

61. Mel'kumov T (1965) Pioneers of rocket technology: selected works, vol 9285. National Aeronautics and Space Administration, Washington, DC

62. Merton RK (1957) Priorities in scientific discovery: a chapter in the sociology of science. Am Sociol Rev 22(6):635-659

63. Minovitch M (1961) A method for determining interplanetary free-fall reconnaissance trajectories. JPL Tech Memo 312:130

64. Minovitch M (1965) Utilizing large planetary pertubations for the design of deep-space, solar-probe, and out-of-ecliptic trajectories. NASA technical report no 32-849

65. Minovitch MA (1963) The determination and potentialities of advanced free-fall iinterplanetary trajectories. In: Proceedings of the first graduate academy of the University of California, Spring Recess

66. Minovitch MA (2010) The invention that opened the solar system to exploration. Planet Space Sci 58(6):885-892

67. Negri RB, Prado AFBA, Sukhanov A (2017) Studying the errors in the estimation of the variation of energy by the "patched-conics" model in the three-dimensional swing-by. Celest Mech Dyn Astron 129(3):269-284

68. Negri RB, Sukhanov A, Prado AFBA (2019) Lunar gravity assists using patched-conics approximation, three and four body problems. Adv Space Res 64(1):42-63

69. Neufeld MJ (1990) Weimar culture and futuristic technology: the rocketry and spaceflight fad in Germany, 1923-1933. Technol Cult 31(4):725-752

70. Neufeld MJ (1995) The rocket and the Reich: Peenemünde and the coming of the ballistic missile era. Simon and Schuster, New York

71. Neufeld MJ (2012) The three heroes of spaceflight: The rise of the Tsiolkovsky-Goddard-Oberth interpretation and its current validity. Quest: The History of Spaceflight Quarterly

72. Neufeld MJ (2018) Spaceflight: a concise history. MIT Press, Cambridge

73. Newton HA (1878) Art. xv.—on the origin of comets. Am J Sci Arts (1820-1879) 16(93):165

74. Niehoff J (1965) An analysis of gravity assisted trajectories in the ecliptic plane. IIT Research Institute. Report no T-12

75. Perozzi E (1986) Cassini mission: dynamics of the titan close encounter. ESA Spec Publ 242:283

76. Prado AFBA (2007) A comparison of the "patched-conics approach" and the restricted problem for swing-bys. Adv Space Res 40(1):113-117
77. Rauschenbakh V, Ovchinnikov MY, McKenna-Lawlor SM (2006) Essential spaceflight dynamics and magnetospherics, vol 15. Springer, Berlin

78. Reichhardt T (1994) Gravity's overdrive. Air Space 8:72-78

79. Richmond Y (2010) Cultural exchange and the cold war: raising the iron curtain. Penn State Press, University Park

80. Ross $\mathrm{S}$ et al (1962) A study of interplanetary transportation systems. Final Rep 3:17-62

81. Ross SD, Scheeres DJ (2007) Multiple gravity assists, capture, and escape in the restricted three-body problem. SIAM J Appl Dyn Syst 6(3):576-596

82. Ruppe HO (1961) Interplanetary flight. In: Koelle H-H (ed) Handbook of astronautical engineering. McGraw-Hill, pp 9-32

83. Rynin NA (1970) Interplanetary flight and communication-rockets, vol 2. Israel Program for Scientific Translations, Jerusalem

84. Rynin NA (1970) Interplanetary flight and communication - theory of space flight, vol 3. Israel Program for Scientific Translations, Jerusalem

85. Schwehm G, Schulz R (1999) Rosetta goes to comet Wirtanen In: Altwegg K, Ehrenfreund P, Geiss J, Huebner WF (eds) Composition and origin of cometary materials. Springer, Berlin, pp 313-319

86. Shepherd L (1994) Prelude and first decade, 1951-1961. Acta Astronaut 32(7-8):475-499

87. Siddiqi AA (2000) Challenge to Apollo: the Soviet Union and the space race, 1945-1974. The NASA history series. NASA SP: 2000-4408

88. Siddiqi AA (2010) The Red Rockets' Glare: Spaceflight and the Russian Imagination, 1857-1957. Cambridge University Press, Cambridge

89. Sohn RL (1964) Venus swingby mode for manned mars missions. J Spacecr Rockets 1(5):565-567

90. Strange NJ, Longuski JM (2002) Graphical method for gravityassist trajectory design. J Spacecr Rockets 39(1):9-16

91. Sweetser TH (1993) Jacobi's integral and deltaV-earth-gravityassist trajectories. In: 1993 AAS/AIAA astrodynamics conference

92. Sykora F (1977) Guido von Pirquet: Austrian pioneer of astronautics. NASA, Washington essays on the history of rocketry and astronautics, vol 1, pp 140-155

93. Tsander FA (1964) Problems of flight by jet propulsion. In: Flights to other planets (The theory of interplanetary travel), 2nd edn. Israel Program for Scientific Translations, Jerusalem. English translation of Problema poleta pri pomoshehi reaktivnykh apparatov

94. von Pirquet G (1928) Die Rakete. In: Die Jupiterreise, vol 2, pp 183-190

95. von Pirquet G (1929) Die Rakete. In: Die Jupiterreise, vol 3, pp 9-13

96. von Pirquet G (1950) Meteors and space-travel. J Br Interplanet Soc 9(4):153-154

97. Wenzel K, Marsden R, Page D, Smith E (1992) The ULYSSES mission. Astron Astrophys Suppl Ser 92:207

98. Winter FH (1983) Prelude to the space age: the rocket societies, 1924-1940. Smithsonian Institution Press, Washington, DC

99. Yegorov VA (1957) Some problems relating to the dynamics of the flight to the moon. In: Proceedings of the 8th international astronautical Congress, Barcelona. Springer, Berlin, p 480

Publisher's Note Springer Nature remains neutral with regard to jurisdictional claims in published maps and institutional affiliations. 